\section{Collared Peccaries}

ALL interested in the breeding of wild animals in captivity will welcome the announcement that two collared peccaries have just been born in the Gardens of the Zoological Society of London, for it is many years since a like event took place there. Though 'pigs' in the general sense of the term, the peccaries, of which there are two species, are found only in North and South America. They differ from the pigs of the Old World in many particulars. In the matter of their dentition they have fewer teeth than the true swine, and the upper tusks turn downwards, not outwards and upwards, as in, say, the wild-boar. They have small ears, and no more than a vestige of a tail ; and only three instead of four hind-toes. Further, no more than two are produced at a birth, and these are never striped as are so many wild swine of the Old World. They display yet another peculiarity in having a large scent-gland in the middle of the back, producing a most evil-smelling exudation. If this gland is not removed immediately after death, the whole flesh becomes tainted and uneatable. The collared peccary, which ranges from Texas to Patagonia, is a harmless animal ; but its larger relative, the white-tipped peccary, has a bad reputation on account of its ferocity. It has, however, a more restricted geographical distribution, extending northwards no farther than Honduras, while its southward limit is Paraguay. But it roams in large herds, unlike its smaller relative which lives in small communities. Both species haunt dense forests, feeding on roots and fruits, hence, in the neighbourhood of inhabited areas they do great damage to crops.

\section{Birth of a Chimpanzee}

"WEDNESDAY", a chimpanzee in the Scottish National Zoological Park at Edinburgh, gave birth to a 'baby' on January 17. 'The only other records of chimpanzee births in Great Britain are "Adam", born in Clifton (Bristol) in May 1934, and "Jubilee", (a female) born in the London Zoo last February. "Wednesday" is of gentle disposition, and her temper has been quiet throughout gestation; she has fed well, and been normal in every way. The birth is a month earlier than was expected, but the 'baby' was born without trouble, and seems to be fully developed and quite fit in every way. "Wednesday" was brought up from an early age by $\mathrm{Mr}$. Wm. Galloway of Glasgow and Accra, and was presented to the Zoological Park in July 1934, when she was about eight years old.

\section{Operation of the Lucerne Plan in Broadcasting}

THE broadcasting stations of Europe have now been working for two years in accordance with the Lucerne plan, by which a redistribution of wavelengths was put into operation on the night of January 14-15, 1934 (see NATURE of December 2, 1933, and January 20, 1934). A review of the working of this arrangement during the past two years is given in World Radio of January 17. The Lucerne plan has been more nearly applied than its predecessors of Geneva, Brussels and Prague, but the recommendations of the plan have not been fully adopted even by some of the countries which signed it. This failure is chiefly confined to the long-wave broadcast band, in which portions of three separate international arrangements now co-exist. On the medium waves, the position is much clearer and, generally speaking, the broadcasting stations are in their allotted places. The exceptions are chiefly confined to cases in which frequencies were allotted in the plan to stations not yet built, and these are now being used temporarily by other stations. A noteworthy development which has resulted from the application of the Lucerne plan is in the increased stability of frequency of broadcast transmitters which has taken place. The plan recommended a tolerance of \pm 50 cycles per second for stations using exclusive waves, and of \pm 10 cycles per second for stations using shared waves. A table of observations given in the article referred to above shows that in Novem. ber 1935, 107 stations had attained the first limit, while 67 stations came within the smaller tolerance. Actually 12 stations showed a maximum deviation from their normal frequencies of 1 cycle per second or less. On the whole, it may be said that the results of international co-operation on the technical aspects of broadcasting in Europe have been fairly satisfactory ; for some 230 stations in thirty-five different countries are now working relatively free of interference.

\section{Electricity Production in North America and Great Britain}

AN interesting comparison is made by Mr. H. E. M. Kensit in World Power of November of the comparative progress made in electricity production by Great Britain, Canada and the United States. The diagrams of electricity production during the past ten years prove that while both the United States and Canada show actual retrogression in consumption during the period 1929-32 of the world-wide depression in industry, Britain made continuous progress throughout it. The average annual progress of Britain over the last ten years has been greater than in either of the other countries. In total production also, Britain is gaining. The conditions affecting the comparison in the three countries are not quite the same. The United States includes in its records of consumption a considerable amount of power generated in Canada and imported. It also includes that portion of the power generated by private manufacturers which is sold by them. Corresponding amounts do not appear in the British items. For the last ten years the average progress in Britain is 10 per cent, in Canada.8.5 and in the United States $4 \cdot 5$. The total outputs in 1934 for the three countries are $17,000,21,000$ and 91,000 million kilowatt hours respectively. The good showing on the British side is attributed by the Americans to British Government enterprise and to the energy and able administration of the Electricity Commissioners. In Canada, owing to the abundance of cheap water-power, about 30 per cent of the total power is exported or used for operating steam electric boilers in connexion with pulp and paper mills. 